\title{
O panorama da fluoretação das águas de abastecimento público da cidade de Belém, estado do Pará, Brasil
}

\author{
The panorama of the fluoridation of public water supplies in Belém, Pará State, Brazil \\ Ayrton Breno Teixeira Rodrigues' (1D), Mayara Sabrina Luz Miranda' (D), Danielle Tupinambá Emmi' (D), Regina Fátima Feio \\ Barroso ' (D), Helder Henrique Costa Pinheiro' (D), Marizeli Viana de Aragão Araújo' (ID) \\ ' Universidade Federal do Pará, Instituto de Ciências da Saúde, Faculdade de Odontologia, Belém, Pará, Brasil
}

\begin{abstract}
RESUMO
INTRODUÇÃO: A fluoretação da água de abastecimento público é uma estratégia em saúde pública no controle da cárie dentária, sendo uma das mais importantes medidas já promovidas. Desde a metade do século XX, o flúor vem sendo utilizado na água de abastecimento e diversos estudos têm demonstrado sua eficácia no controle da cárie. Diante desse cenário, observa-se que quando há a interrupção da fluoretação, ou quando os teores de flúor ficam abaixo do recomendado, os benefícios podem ser perdidos e a prevalência de cárie aumenta. OBJETIVO: Realizar um estudo sobre a conjuntura da fluoretação na cidade de Belém, estado do Pará, tendo como foco aspectos importantes do íon flúor, a consolidação da fluoretação no Brasil e no mundo e a vigilância dos teores de flúor. MÉTODOS: Foi realizada a análise dos laudos gerados pela Secretaria de Saúde Pública do Pará dos teores de flúor de 2005 e 2006 e da documentação trocada entre a Faculdade de Odontologia da Universidade Federal do Pará e a empresa responsável pelo tratamento de água do município de Belém; além de levantamentos bibliográficos em bases de dados eletrônicas. RESULTADOS: Os dados evidenciaram que a fluoretação no município não estava sendo realizada de maneira adequada durante os anos pesquisados e foi interrompida em 2010, com flagrante aumento do índice CPO-D no período. CONCLUSÃO: É inegável a urgência da reativação da fluoretação pela concessionária, bem como uma vigilância eficiente relacionada aos teores de flúor fornecidos à população por meio do abastecimento da água fluoretada.
\end{abstract}

Palavras-chave: Saúde Pública; Fluoretação; Flúor; Cárie Dentária; Abastecimento de Água.

\begin{abstract}
INTRODUCTION: Community water fluoridation is a public health strategy to control dental caries and is one of the most important measures ever implemented. Since the mid-twentieth century, fluoride has been used in water supplies, and several studies have demonstrated its effectiveness in controlling caries. Given this scenario, it is observed that when an interruption of fluoridation occurs or when fluoride levels are below the intake recommendations, benefits may be lost, and the prevalence of caries increases. OBJECTIVE: To analyze the fluoridation situation in Belém, Pará State, focusing on the aspects of fluoride ion, the consolidation of water fluoridation in Brasil and worldwide, and the monitoring of fluoride levels. METHODS: Reports generated by the Department of Public Health of Pará, containing fluoride levels from 2005 to 2006, and documents exchanged between the Faculty of Dentistry at Universidade Federal do Pará and the water treatment company of Belém. RESULTS: The data showed that fluoridation in the municipality was not being adequately performed during the years studied, and it was interrupted in 2010, which caused a significant increase in the DMFT index at that time. CONCLUSION: The urgency of reactivating fluoridation by the water company is undeniable and efficient monitoring of the fluoride levels supplied to the population through fluoridated water.
\end{abstract}

Keywords: Public Health; Fluoridation; Fluorine; Dental Caries; Water Supply.

\section{Correspondência / Correspondence:}

Marizeli Viana de Aragão Araúio

Universidade Federal do Pará, Instituto de Ciências da Saúde, Faculdade de Odontologia

Av. Augusto Corrêa, 1. Bairro: Guamá. CEP: 66075-110 - Belém, Pará, Brasil - Tel.: +55 (91) 3201-7992

E-mail:marizeli@ufpa.br 


\section{INTRODUÇÃO}

A partir do século XX, a Odontologia começou a tentar compreender a origem da cárie dentária, visto que a prevalência era bastante alta nos Estados Unidos da América (EUA) e na maioria dos países desenvolvidos, afetando populações do mundo todo. A cárie dentária, consequentemente, foi considerada um problema de saúde pública ${ }^{1}$.

Os estudos observacionais realizados constataram uma relação entre flúor e cárie dentária; porém, antes da descoberta dos seus benefícios para o elemento dental, as pesquisas revelaram a sua influência em causar um efeito adverso, que foi denominado fluorose dentária. Os estudos que se sucederam foram essenciais, pois estimaram os valores ótimos de flúor na água capazes de promover o máximo de benefício contra a cárie dentária e o mínimo de risco de fluorose dentária ${ }^{2}$.

A fluoretação das águas de abastecimento público é a adição controlada de um composto de flúor à água para consumo humano, e constitui uma medida responsável pelo declínio da cárie dentária durante a metade do século XX3 . No Brasil, essa medida provocou reduções significativas na experiência de cárie na população das cidades que a adotaram, principalmente entre os anos de 1986 e 2003. No país, a fluoretação recebeu determinação legal há mais de 40 anos e vem sendo efetiva em várias localidades. Além disso, tal medida preventiva é de grande importância em virtude de seu aspecto social na redução de desigualdades em saúde pública, visto que se trata de uma estratégia que atinge a população de forma extensa e regular ${ }^{4}$.

Com base no exposto, a iniciativa de fluoretar as águas de abastecimento é uma medida promotora de saúde bucal, principalmente no Brasil que possui uma intensa desigualdade social. Além disso, essa estratégia constitui, muitas vezes, o principal mecanismo de se obter flúor por grande parte da população que não tem acesso a outros meios preventivos, como o dentifrício fluoretado ${ }^{4}$.

Diversos estudos têm mostrado que a fluoretação das águas de abastecimento público é um método eficaz de prevenção da cárie dentária. Assim, o objetivo deste estudo é realizar uma revisão crítica, abordando os aspectos químicos do íon flúor, a legislação da fluoretação no Brasil, o impacto dessa medida na saúde pública e o panorama atual da fluoretação na cidade de Belém, estado do Pará, Brasil.

\section{MÉTODOS DE PESQUISA}

Para a obtenção dos dados, foi realizada a análise documental dos laudos de teores de flúor gerados pela Secretaria de Saúde Pública do Pará (SESPA) nos anos de 2005 e 2006, bem como da documentação trocada entre a Faculdade de Odontologia da Universidade Federal do Pará (UFPA) e a Companhia de Saneamento do Pará (COSANPA), responsável pelo tratamento de água da cidade de Belém. Além disso, foi feito um levantamento bibliográfico nas bases de dados PubMed, Scientific Electronic Library Online, Biblioteca
Virtual em Saúde (Bireme), Periódicos Capes e Literatura Latino-Americana e do Caribe em Ciências da Saúde, correspondente ao período de 1987 a 2020, utilizando os termos de busca "flúor", "fluoretação", "fluoretação das águas" e "cárie dentária".

\section{O ELEMENTO QUÍMICO FLÚOR}

O flúor está presente na água, no ar e no solo, tendo enorme capacidade de reagir com outros elementos e formar compostos orgânicos e inorgânicos ${ }^{5}$. Dentre os íons carregados negativamente, o flúor é o elemento mais reativo. $\mathrm{Na}$ natureza, não é encontrado sozinho, mas sim em compostos denominados fluoretos ${ }^{6}$.

Quando disponível na sua forma livre, o flúor é altamente corrosivo7. Quando está incorporado ao solo, ar e à água, o flúor apresenta diferentes concentrações, dependendo da sua localização geográfica. Na água do mar, sua concentração é de aproximadamente 1,0 ppm, porém pode variar entre 0,8 e 1,4 ppm 5 .

Com a comprovação dos efeitos do fluoreto no controle da cárie, os fluoretos foram adicionados às águas de abastecimento, aos produtos de higiene oral (dentifrícios e enxaguatórios bucais), aos alimentos e medicamentos $^{8}$. Vale ressaltar que os principais meios de se obter o fluoreto são os cremes dentais fluoretados e água fluoretada.

A água tem uma importância inegável para as políticas de saúde pública; porém, possui níveis inadequados de teores de fluoreto que não subsidiam a prevenção da cárie dentária. Para tanto, propõe-se realizar os ajustes dos teores até uma concentração ideal para cada localidade, observando a temperatura? Tais teores devem respeitar princípios que visem ao estabelecimento dos benefícios da prevenção e redução da cárie com o mínimo de risco de fluorose dentária ${ }^{2}$.

A cárie dentária, conceituada como uma doença infectocontagiosa e multifatorial, provoca a desmineralização da estrutura dentária, devido à ação dos ácidos derivados do metabolismo de carboidratos da placa bacteriana ${ }^{5,10}$. Porém, após a correlação entre flúor e cárie dentária, no início do século XX, diversos levantamentos epidemiológicos têm fornecido dados que comprovam a efetividade da adição do fluoreto nas águas de abastecimento para consumo humano no que se concerne à redução do índice da cárie dentária ${ }^{3}$.

É por meio de um desequilíbrio químico que a cárie dentária é originada, e, a partir disso, inicia-se um processo dinâmico de perdas e ganhos de minerais entre a saliva e a estrutura dentária. Equivocadamente, acreditava-se que a ação do flúor no processo da cárie demonstraria sua menor incidência ao ser incorporada em forma de fluorapatita (FA). Entretanto, a ingestão de flúor durante a formação dos dentes não forma FA, pois apenas uma quantidade de aproximadamente $10 \%$ é incorporada, a qual é insuficiente para tornar o esmalte mais resistente ao ataque ácido proveniente do metabolismo bacteriano. No entanto, a presença do flúor no meio (saliva, placa bacteriana) 
é um fator essencial na dinâmica do processo de desmineralização-remineralização (des-re), ativando a remineralização e reduzindo a desmineralização ${ }^{11}$.

A estrutura mineral dentária depende do ambiente oral, sendo relacionada com as variações do $\mathrm{pH}$. A queda do $\mathrm{pH}$ da placa bacteriana, provocada pela liberação do ácido derivado do metabolismo das bactérias, ocasiona a dissolução da hidroxiapatita $(H A)$, liberando fosfato e cálcio para o meio. Todavia, a presença do flúor no ambiente bucal simultaneamente causará a deposição de certa quantidade de mineral na forma de fluorapatita, dessa forma compensando a perda mineral do elemento e interferindo no desenvolvimento da cárie. Além desse fator, a simples presença do flúor ativa a capacidade de remineralização da saliva quando $\circ \mathrm{pH}$ retorna a sua normalidade, intensificando a capacidade de resposta da saliva em repor os minerais perdidos ${ }^{3}$.

Assim, é notável que a presença do flúor no meio bucal é essencial para o seu efeito preventivo contra a cárie ao longo da vida do indivíduo. Não obstante, sabe-se que o flúor não atua impedindo a doença isoladamente, havendo a necessidade da manutenção do controle da placa bacteriana e equilíbrio na dieta cariogênica para que o efeito preventivo se manifeste em sua totalidade 5 .

As primeiras pesquisas sugeriram que a propriedade preventiva do flúor era decorrente da sua ingestão durante o período do desenvolvimento dentário, culminando em uma estrutura dental mais resistente ao ataque da cárie. Contudo, sabe-se, atualmente, que o poder preventivo do flúor é decorrente da sua presença constante no ambiente oral, sendo disponibilizado por meio da ingestão da água fluoretada (sistêmico) ou meios tópicos, como a aplicação tópica de flúor, bochechos e dentifrício fluoretado². Após a ingestão de água fluoretada ou consumo de alimentos feitos com água fluoretada, observa-se a elevação da biodisponibilidade de flúor no plasma sanguíneo e principalmente na saliva, possibilitando a diminuição da perda de minerais e a reversão do progresso da doença cárie $^{12}$

A fluoretação das águas consiste na adição e controle dos teores a um valor predeterminado de fluoreto nas águas de abastecimento público com a finalidade de promover efeitos preventivos à população, como a prevenção e controle da cárie dentária9. No Brasil, é regulamentada a utilização do fluoreto de sódio $(\mathrm{NaF})$, fluoreto de cálcio $\left(\mathrm{CaF}_{2}\right)$, ácido fluorsilícico $\left(\mathrm{H}_{2} \mathrm{SiF}_{6}\right)$ e do fluorsilicato de sódio $\left(\mathrm{Na}_{2} \mathrm{SiF}_{6}\right)$ para a fluoretação das águas de abastecimento público ${ }^{13}$. No entanto, o fluorsilicato de sódio e o ácido fluorsilícico são os produtos mais utilizados ${ }^{14}$. A prática de fluoretar a água de abastecimento consistiu em uma das mais importantes medidas em saúde pública e uma das dez conquistas mais relevantes em saúde pública no século $X X^{3,4}$.

A efetividade da fluoretação das águas foi demonstrada por meio dos estudos realizados em diversas cidades norte-americanas nos anos 1940.
Os resultados obtidos, após 13 anos de observações, descreveram uma redução na ocorrência de cárie de 50 a $70 \%$ em crianças residentes naquelas cidades que adotaram a fluoretação das águas?

No Brasil, os municípios que incluíram a fluoretação no sistema de abastecimento público de água tiveram uma redução significativa na prevalência de cárie dentária. Muito embora houvesse a presença de outros métodos de obtenção do flúor, a fluoretação das águas se tornou o melhor meio coletivo de prevenção da cárie, tendo um grande impacto na comunidade e se destacando pelo seu custo-benefício satisfatório?.

\section{HISTÓRICO DA FLUORETAÇÃO NO MUNDO E NO BRASIL (LEGISLAÇÃO)}

primeiro passo para a fluoretação das águas ocorreu por meio das observações de profissionais da área odontológica, que notaram a presença de esmalte manchado nos dentes permanentes de diversos pacientes ${ }^{5}$. $\bigcirc$ cirurgião-dentista Dr. Frederick S. McKay, após anos de investigação, propôs que um agente presente na água de consumo seria a causa do aparecimento de esmalte manchado'. McKay também foi o pioneiro em associar que crianças acometidas com o problema no esmalte possuíam menos susceptibilidade à cárie dentária ${ }^{5}$.

Após anos de estudo, a hipótese de McKay foi confirmada pelo químico $\mathrm{H}$. V. Churchill, o qual, ao utilizar um novo método de análise, detectou altas concentrações de fluoreto na água de consumo'. Em 1931, o Dr. H. Trendley Dean investigou a associação do flúor com o esmalte manchado ${ }^{3}$. Dean concluiu que crianças residentes em regiões com flúor presente na água eram menos susceptíveis à cárie dentária e propôs uma concentração de flúor que produzisse máximo efeito preventivo contra cárie e o mínimo de risco para o manchamento do esmalte, o qual ele denominou, posteriormente, de fluorose dentária ${ }^{5}$.

Em 1945, após anos de estudos, a cidade de Grand Rapids, no estado de Michigan, EUA, tornou-se o primeiro município a fluoretar as suas águas de abastecimento artificialmente. Isso fez parte de um estudo, que teve como cidade controle não fluoretada - município de Muskegon. Também participaram do estudo outras cidades norte-americanas e canadenses ${ }^{15}$.

Decorridos 13-15 anos de estudo, concluiu-se que houve redução de 50 a $70 \%$ de cárie entre as crianças residentes nas cidades com água fluoretada ${ }^{1}$. Nos EUA, na década de 1950, a fluoretação das águas passou a ser política oficial e, em 2006, cerca de $60 \%$ dos seus residentes eram beneficiados por essa medida². Além disso, a política de fluoretação nos EUA foi progredindo com o passar dos anos, abrangendo 74,4\% da população em 2012, totalizando aproximadamente 210 milhões de residentes ${ }^{16}$.

No Brasil, em 1952, no X Congresso Brasileiro de Higiene realizado em Belo Horizonte, estado de Minas Gerais, houve a primeira menção em se recomendar a fluoretação das águas de abastecimento público, processo esse que teve início em $1953^{5}$. 
Os passos iniciais para a adição do flúor nas águas de abastecimento público ocorreram com a implantação do sistema de fluoretação no município de Baixo Guandu, no estado do Espírito Santo. A Fundação Serviços de Saúde Pública (FSESP), do Ministério da Saúde (MS), implantou o sistema em 31 de outubro de 19533. O teor de fluoreto para a região foi na proporção de 0,8 ppm e o composto utilizado foi o fluorsilicato de sódio $3,17,18$. Antes da implantação do sistema, foi realizado um levantamento epidemiológico preliminar da prevalência de cárie em escolares de 6 a 14 anos de idade, e, decorridos sete anos, houve outro levantamento epidemiológico, constatando uma redução de 64\% no índice de dentes permanentes cariados, perdidos e obturados (CPO-D) ${ }^{13}$.

Em outubro de 1958, a cidade de Curitiba, estado do Paraná, implantou o sistema, sendo considerada a primeira capital a fluoretar suas águas ${ }^{19}$. Diversos municípios passaram a adotar a fluoretação das águas no decorrer dos anos de 1950 a 1980. Em 12 de junho de 1957, o estado do Rio Grande do Sul estabeleceu a obrigatoriedade da fluoretação de suas águas 5 .

A partir de 1974, a fluoretação das águas nas estações de tratamento tornou-se obrigatória no Brasil. A Lei federal n 6.050, de 24 de maio de 1974, dispõe sobre a fluoretação das águas em sistemas públicos de abastecimento onde houver tratamento de água ${ }^{3}$. $\bigcirc$ Decreto federal $n^{\circ} 76.872$, estabelecido em 1975, regulamentou a Lei $n^{\circ} 6.050$ de 1974 e determinou a obrigatoriedade da fluoretação. Ainda em 1975, estabeleceu-se a Portaria $n^{\circ}$ 635/BSB, de 26 de dezembro de 1975, que ditou normas e padrões para estipular concentrações adequadas de acordo com a temperatura média do local e compostos recomendados para uma adequada fluoretação ${ }^{2,3}$.

Apesar da Lei federal ter sido estabelecida em 1974, seus efeitos foram gradualmente se expandindo, e a medida decorreu lentamente e com diversas diferenças regionais, privando desse benefício municípios do interior do país ${ }^{4}$. $\bigcirc$ Governo Federal passou a promover recursos financeiros, colocando o Brasil entre os países que investem em fluoretação das águas de abastecimento público como medida de saúde pública ${ }^{20}$.

Após a Lei de 1974, programas foram estabelecidos para incentivar o fornecimento de água tratada fluoretada a um maior contingente populacional. A primeira medida foi conduzida pela FSESP e executada pelo MS em parceria com o Instituto Nacional de Alimentação e Nutrição em 1975. Decorrida uma década, o Fundo de Investimento Social (Finsocial), por meio do Banco Nacional de Habitação, liberou recursos para as companhias de tratamento de água adicionarem flúor à água ${ }^{21}$.

A fluoretação das águas de abastecimento público no Brasil foi defendida por diversas entidades profissionais da área odontológica e recomendada pela I, II e III Conferência Nacional de Saúde Bucal, realizadas, respectivamente, em 1986, 1993 e $1994^{14}$.

Atualmente, a fluoretação das águas constitui em eixo norteador da Política Nacional de Saúde Bucal, denominada Brasil Sorridente, e vem incentivando a implantação da fluoretação nos municípios com tratamento de água. De 2003 a 2007, foram implantados 206 novos sistemas em oito estados brasileiros, abrangendo 2,4 milhões de pessoas ${ }^{3,22}$.

Diversas entidades da área da saúde têm preconizado que a fluoretação das águas de abastecimento possui caráter preventivo, eficiente e seguro no controle da cárie e que essa medida, além de ser implantada, deve ser mantida ${ }^{23}$. Além disso, a interrupção do método acarreta a perda dos benefícios e pode ocasionar o aumento da prevalência da cárie $^{3}$.

De acordo com os levantamentos epidemiológicos de saúde bucal realizados em 2003 e 2010 pelo Ministério da Saúde, observou-se a diminuição nos valores do índice CPO-D nas capitais que adotavam a fluoretação das águas em comparação com as capitais que não realizavam ou interromperam, culminando em uma elevação do índice em 12,8\% na população de 12 anos de idade ${ }^{24}$.

Segundo o levantamento epidemiológico de saúde bucal de 2010 (SB Brasil 2010), as Regiões Norte $(3,16)$, Centro-Oeste $(2,63)$ e Nordeste $(2,63)$ apresentaram os índices mais elevados de ocorrência de cárie dentária em adolescentes de 12 anos de idade. Em muitos municípios dessas regiões, havia ausência de fluoretação, correlacionando-se com o aumento da experiência de cárie da população ${ }^{25}$.

\section{A VIGILÂNCIA DOS TEORES DE FLÚOR NAS ÁGUAS DE ABASTECIMENTO}

Com o crescimento da fluoretação das águas no mundo e principalmente no Brasil, a vigilância dos teores de flúor na água para consumo torna-se primordial, devido aos seus aspectos sociais de grande interesse para a saúde pública. A inexistência ou a ineficiência de monitoramento do fluoreto na água pode culminar no aumento do risco de fluorose, em casos de teores excessivos, ou o comprometimento dos benefícios do flúor na prevenção da cárie dentária, em função de teores abaixo do ideal ${ }^{26}$.

Embora tenha havido uma mudança considerável no quadro epidemiológico para a cárie dentária no Brasil, dados confirmam que há melhoria da saúde bucal em locais onde existe a fluoretação da água e onde ela é monitorada regularmente, sendo necessária uma concentração ótima de flúor, que pode variar de 0,7 a 1,0 ppm, dependendo da média de temperatura. Regiões com temperaturas mais baixas devem ter níveis de flúor mais elevados, enquanto regiões com temperaturas mais elevadas devem apresentar níveis mais baixos ${ }^{27}$.

Desde 1975, com a Portaria n635/BSB, a fluoretação da água passou a ser regulamentada por normas e padrões que visavam a determinar a concentração ideal para cada região, preconizando até o composto ideal para a implementação da fluoretação. Entretanto, os padrões foram se modificando ao longo do tempo e, atualmente, está em vigência a Portaria GM/MS n².914, de 12 de 
dezembro de 2011, que determina os valores de concentração de fluoreto, os quais devem estar de acordo com a Portaria $n^{\circ}$ 635/1975, que define que a concentração do íon não pode ultrapassar o valor máximo permitido (VMP) de 1,5 mg/ $\mathrm{L}^{28}$.

O MS, em 2000, implementou o Programa Nacional de Vigilância em Saúde Ambiental relacionado à qualidade da água para consumo humano (VIGIAGUA), responsável, desde então, pela vigilância da qualidade da água no Brasil. $\bigcirc$ monitoramento dos teores de flúor nas águas de abastecimento público é parte integrante do Programa, monitorando os teores de flúor para que estejam de acordo com os padrões e normas vigentes. Em razão disso, para assegurar as informações a respeito da qualidade da água, foi criado um Sistema de Informação de Vigilância da Qualidade da Água para Consumo Humano (SISAGUA) ${ }^{27}$.

O SISAGUA é um sistema de informação que registra dados relativos à qualidade da água. Como parte integrante desse Sistema, estão inseridos campos em que é possível registrar os teores de flúor, a partir das análises das águas de abastecimento público, coletados nos municípios com fluoretação. Assim, tal sistema tem um papel importante na saúde, pois, por meio da análise desses dados, é possível promover ações de controle de agravos para a saúde pública $^{22}$.

A vigilância dos teores de flúor nas águas de abastecimento é uma estratégia vital que objetiva analisar os casos de ocorrência de concentrações excessivas ou insatisfatórias de flúor, que podem culminar em prejuízos à população que a utiliza. A empresa que operacionaliza a produção, o tratamento e a distribuição da água de abastecimento deve realizar o monitoramento dos teores de flúor por meio das análises de águas coletadas periodicamente. Porém, é relevante a realização do heterocontrole promovido por aqueles que não pertencem à empresa responsável e com isso comparar os dados e verificar a efetividade da fluoretação das águas ${ }^{28}$.

No estado do Pará, em 1987, foi criado o Grupo Estadual de Controle de Fluoretação do Pará (GECOF) com o propósito de realizar o acompanhamento e a avaliação das normas e padrões estabelecidos para a fluoretação das águas de abastecimento público do estado. O grupo era composto por representantes dos órgãos de classe odontológicos (Associação Brasileira de Odontologia - Seção Pará, Conselho Regional de Odontologia do Pará, Sindicato dos Odontologistas do Pará), UFPA, Centro Universitário do Estado do Pará, Secretaria de Saúde do Estado do Pará (Divisão de Saúde Bucal e Vigilância Sanitária), Secretaria Municipal de Saúde de Belém, Secretaria Municipal de Saúde de Ananindeua, Fundação Nacional de Saúde, Academia Paraense de Odontologia, COSANPA, Serviço de Abastecimento de Água e Esgotamento Sanitário (SAAEB), Exército, Marinha e Aeronáutica. $\bigcirc$ GECOF exerceu o heterocontrole da fluoretação das águas de abastecimento no Pará de maneira eficaz até 2009, quando deixou de realizar reuniões mensalmente.

\section{FLUORETAÇÃO DAS ÁGUAS EM BELÉM: PANORAMA ATUAL}

A fluoretação das águas de abastecimento público é uma medida essencial de promoção de saúde que implica o declínio da prevalência de cárie dentária. No Brasil, tal medida é amparada por lei e normas, sendo obrigatória nas cidades em que existe estação de tratamento de água (ETA).

município de Belém, capital do estado do Pará, é dividido em 71 bairros distribuídos em oito distritos administrativos. Segundo a Prefeitura Municipal de Belém, os distritos englobam os bairros com características semelhantes e são divididos em Distrito Administrativo de Belém (DABEL), Distrito Administrativo do Guamá (DAGUA), Distrito Administrativo da Sacramenta (DASAC), Distrito Administrativo do Entroncamento (DAENT), Distrito Administrativo do Benguí (DABEN), Distrito Administrativo de Icoaraci (DAICO), Distrito Administrativo de Outeiro (DAOUT) e Distrito Administrativo de Mosqueiro (DAMOS) ${ }^{29}$. $\bigcirc$ município concentra uma população de 1.499.641 habitantes e ocupa uma área de aproximadamente $1.059,466 \mathrm{~km}^{2}$ segundo dados estimados do Instituto Brasileiro de Geografia e Estatística (IBGE) para o ano de $2020^{30}$.

A COSANPA é a concessionária que gerencia e operacionaliza a produção, o tratamento e a distribuição de água para atender a população. A água distribuída pela rede de abastecimento é captada dos lagos Água Preta e Bolonha, localizados em área de proteção ambiental. Atualmente, em torno de $90 \%$ da população residente da Região Metropolitana de Belém é coberta por água proveniente da Concessionária $^{31}$.

A fluoretação das águas do município de Belém iniciou em 1985, sob responsabilidade da COSANPA. As primeiras estações de tratamento de água (ETA) a iniciarem o processo de fluoretação foram ETA São Braz, ETA $5^{\circ}$ Setor e ETA Bolonha. Decorridos 11 anos da implantação, em 1996, o percentual da população coberta por água fluoretada correspondia a $82 \%{ }^{13}$

Em 2003, foi realizada uma pesquisa que avaliou a concentração de flúor nas águas de abastecimento público com amostras coletadas em dez bairros de Belém escolhidos aleatoriamente: Marambaia, Telégrafo, Nazaré, São Braz, Canudos, Guamá, Benguí, Val-de-Cans, Souza e Pedreira, sendo que o bairro do Benguí foi selecionado como controle, por sabidamente não ser coberto pela fluoretação na ocasião. Após as análises das coletas, executadas no Laboratório de Geoquímica da UFPA, verificou-se que 78\% das amostras apresentaram teor médio de flúor inaceitável, tendo como parâmetro de aceitabilidade de 0,6 a 0,8 ppm, sendo a concentração ideal de 0,7 ppm para a região de Belém. Apenas 22\% das amostras, totalizando dois bairros (Nazaré e Souza), apresentaram teores de flúor aceitáveis, com concentrações de 0,62 e $0,74 \mathrm{ppm}^{32}$. 
Por meio do GECOF, a SESPA realizou, em 2005 e 2006, análises do teor de flúor na água de abastecimento público em várias localidades de Belém e distrito de Mosqueiro para realizar o heterocontrole da fluoretação das águas. Os locais escolhidos eram preferencialmente públicos (escolas e torneiras comunitárias) para facilitar a coleta. Os dados obtidos após análises (Tabela 1) permitiram identificar que as amostras possuíam concentrações inadequadas de íon fluoreto, segundo a determinação da Portaria GM/MS $n^{\circ} 635 / 1975$, que estabelece faixas de concentração de flúor em função da temperatura objetivando atingir os níveis mínimos aceitáveis para a prevenção da cárie ${ }^{33}$.

Em 2014, a Prefeitura Municipal de Belém elaborou o Plano Municipal de Saneamento Básico de Abastecimento de Água e Esgotamento Sanitário de Belém baseado na situação de abastecimento de água e esgotamento sanitário de Belém na ocasião. Segundo o documento, o serviço de abastecimento de água era realizado tanto pela COSANPA, gerenciando o abastecimento de água da maior parte de Belém, Ananindeua e Marituba, quanto pelo SAAEB, que administrava sete regiões em Belém, além dos distritos de Mosqueiro, Outeiro e Icoaraci. Atualmente, a COSANPA passou a operar nas regiões anteriormente atendidas pelo SAAEB ${ }^{34}$.

De acordo com a pesquisa, a Vigilância da Fluoretação da Água de Abastecimento Público realizada pelo Centro Colaborador em Vigilância da Saúde Bucal do Ministério da Saúde, da Faculdade de Saúde Pública da Universidade de São Paulo, no período de 2010 a 2015, com o propósito de verificar a cobertura e vigilância da fluoretação das águas de abastecimento público no Brasil, observou que, em Belém, $60 \%$ da população era coberta por tratamento de água; no entanto, não foram encontrados teores de flúor na água tratada disponibilizada para a população. No Pará, apenas os municípios de Cametá, Dom Eliseu, Oriximiná e Paragominas registraram algum teor de flúor ${ }^{16}$.

Tabela 1 - Teor de flúor na água de abastecimento público em localidades do município de Belém em 2005 e 2006

\begin{tabular}{|c|c|c|c|}
\hline Local de coleta & Ano & Teor de flúor (mg/L) & Avaliação \\
\hline Colégio Paes de Carvalho & 2005 & 0,2 & Insatisfatório \\
\hline Faculdade Pan Amazônica & 2005 & 0,2 & Insatisfatório \\
\hline E.E.E.F.M. Tiradentes II & 2005 & 0,1 & Insatisfatório \\
\hline Colégio Ideal JR. & 2005 & 0,2 & Insatisfatório \\
\hline E.E.E.F.M. Adalberto Klautau & 2006 & 0,3 & Insatisfatório \\
\hline Conj. Residencial Raimundo Jinkings & 2006 & 0,0 & Insatisfatório \\
\hline E.E.E. M.M. Antonieta Serra Freire & 2006 & 0,0 & Insatisfatório \\
\hline Conj. Residencial Angelim & 2006 & 0,0 & Insatisfatório \\
\hline E.E.E.F.M. Honorato Figueiras & 2006 & 0,2 & Insatisfatório \\
\hline E.E.E.F.M. Dr. Freitas & 2006 & 0,2 & Insatisfatório \\
\hline E.E.E.F. Prof. Waldemar Ribeiro & 2006 & 0,1 & Insatisfatório \\
\hline E.E.E.F.M. Vilhena Alves & 2006 & 0,3 & Insatisfatório \\
\hline E.M. Benvinda de França Messias & 2006 & 0,2 & Insatisfatório \\
\hline E.M.E.F. Prof. João Nelson Ribeiro & 2006 & 0,2 & Insatisfatório \\
\hline E.E.E.F.M. Augusto Montenegro & 2006 & 0,2 & Insatisfatório \\
\hline E.E.E.F.M. Jarbas Passarinho & 2006 & 0,4 & Insatisfatório \\
\hline E.M.E.F. Prof. ${ }^{a}$ Alzira Pernambuco & 2006 & 0,4 & Insatisfatório \\
\hline E.E.E.F.M. Maroja Neto & 2006 & 0,4 & Insatisfatório \\
\hline E.E.E.F.M. Justo Chermont & 2006 & 0,3 & Insatisfatório \\
\hline E.E.E.F. Graziela Ribeiro & 2006 & 0,4 & Insatisfatório \\
\hline E.E.E. Prof. ${ }^{a}$ Rosalina Alves & 2006 & 0,3 & Insatisfatório \\
\hline
\end{tabular}


A fluoretação das águas de abastecimento público em Belém não está sendo realizada desde o ano de 2010, embora essa medida tenha sido implementada na década de 1980 pela COSANPA ${ }^{35}$. Sabe-se que a interrupção de tal medida pode acarretar a polarização da cárie e que, em locais onde a população não é beneficiada com água fluoretada, o índice CPO-D tende a ser maior do que em locais onde há a presença de sistema de fluoretação ${ }^{24}$.

Ao analisar o contexto do município de Belém na primeira década do século XXI, mais especificamente entre 2003 e 2010, é possível perceber a falta de monitoramento da concentração de fluoreto na água para consumo humano. Os resultados das análises empreendidas, nesse período, comprovaram que a vigilância dos teores adequados de flúor na água de abastecimento fornecida ao município era inadequada, resultando na maior parte das coletas em teores abaixo do preconizado pelo MS. Outrossim, Narvai e colaboradores ${ }^{24}$ enfatizaram que houve a elevação no índice CPO-D no período referido.

Um estudo realizado com adolescentes de Belém, no período de 2012 a 2014, concluiu que a prevalência de cárie dentária foi elevada ${ }^{36}$, estando acima das médias nacional e regional, conforme constatado na última pesquisa nacional de saúde bucal realizada em 2010. Nessa pesquisa, o índice de dentes decíduos cariados, com extração indicada e obturados (ceo-d) aos 5 anos de idade foi de 2,14; e o índice CPO-D foi de 2,45 aos 12 anos, 4,88 para a faixa de 15 a 19 anos, 15,87 para 35 a 44 anos e 27,62 para 65 a 74 anos de idade ${ }^{25}$. Além disso, os dados encontrados indicaram que o componente cariado foi - mais prevalente dentre os demais componentes do índice ceo-d aos 5 anos de idade $(91,6 \%)$ e do índice CPO-D aos 12 anos $(77,1 \%)$ e entre 15 e 19 anos $(59,0)$. Nas faixas etárias correspondentes aos adultos e idosos, o componente predominante do índice foi referente a dentes perdidos, sendo $57,0 \%$ nos adultos e 92,2\% nos idosos ${ }^{25}$. Esses dados indicaram a grande necessidade de ações em saúde bucal para a região, como a reativação do sistema de fluoretação da água de abastecimento paralisado e o melhor acesso aos serviços odontológicos ${ }^{25,36}$.

Em adição, além da falta de monitoramento do teor de flúor na água para consumo e a interrupção da fluoretação no município no ano de 2010, destaca-se o não cumprimento da legislação federal vigente no país, que estabelece a obrigatoriedade da fluoretação onde existe ETA, e da Lei Municipal n 7.530 de 1991, que regulamenta a avaliação e o controle da água tratada e conservada com flúor. Em função disso, o não cumprimento dessas medidas é alarmante e demonstra um exemplo concreto de omissão do poder público e falta do controle social da população em aspectos importantes que afetam a sua saúde.
O custo para a fluoretação das águas de abastecimento é baixo. Estudos demonstraram que o valor per capta variou de R\$ 0,08 em São Paulo ${ }^{14}$, RS 0,60 em Pernambuco ${ }^{27}$ e R\$ 1,43 em Sorocaba ${ }^{37}$. É um investimento que diminui consideravelmente os custos com cuidados odontológicos da população, tanto no sistema de saúde público quanto no privado.

No início de 2018, uma reunião realizada entre a diretora nacional da Associação Brasileira de Engenharia Sanitária e Ambiental, a COSANPA e membros da Agência Reguladora Municipal de Água e Esgoto de Belém e do Instituto Federal do Pará, tratou sobre a paralisação da fluoretação em Belém e a necessidade de se reativar tal medida. A despeito disso, a diretora argumentou que era primordial a realização de um levantamento epidemiológico da experiência de cárie entre o período em que havia a fluoretação e o atual. Apesar disso, até o mês de dezembro de 2020, Belém continuou sem fluoretação nas águas de abastecimento público ${ }^{38}$.

\section{CONCLUSÃO}

Por meio dos dados explanados neste estudo, constatou-se a ineficiência do controle dos teores adequados de flúor na água por parte da companhia de tratamento de água durante a primeira década do século XXI, com a paralisação da fluoretação em 2010 no município de Belém, permanecendo desativada até os dias atuais. Os índices de experiência de cárie observados nos levantamentos epidemiológicos realizados cresceram durante esse mesmo período, reforçando que a retomada do procedimento da fluoretação no município, com um controle rigoroso sobre os teores de flúor, é um meio importante para alterar positivamente a incidência da cárie dentária e minimizar o risco de fluorose.

Assim, considera-se que a fluoretação da água de abastecimento para consumo humano é uma estratégia essencial para a promoção de saúde da população, visto que a saúde é um direito de todos e a sua instituição beneficia todos os setores da sociedade, principalmente o de menor nível socioeconômico.

\section{AGRADECIMENTOS}

À COSANPA, pelas informações prestadas.

\section{CONFLITOS DE INTERESSES}

Não houve conflitos de interesses no presente estudo.

\section{CONTRIBUIÇÃO DOS AUTORES}

ABTR contribuiu na pesquisa de dados e redação; MSLM, na revisão inicial e pesquisa de dados; DTE, na redação e revisão crítica; RFFB, na revisão crítica; HHCP, na concepção do estudo; e MVAA, na concepção do estudo, redação e revisão crítica. 


\section{REFERÊNCIAS}

1 Centers for Disease Control and Prevention. Achievements in public health, 1900-1999: fluoridation of drinking water to prevent dental caries. MMWR Morb Mortal Wkly Rep. 1999 Oct;48(41):933-40.

2 Frazão P, Peres MA, Cury JA. Qualidade da água para consumo humano e concentração de fluoreto. Rev Saude Publica. 2011 out;45(5):964-73.

3 Ramires I, Buzalaf MAR. A fluoretação da água de abastecimento público e seus benefícios no controle da cárie dentária - cinquenta anos no Brasil. Cienc Saude Coletiva. 2007 jul-ago; 12(4):1057-65.

4 Antunes JLF, Narvai PC. Políticas de saúde bucal no Brasil e seu impacto sobre as desigualdades em saúde. Rev Saude Publica. 2010;44(2):360-5.

5 Narvai PC. Cárie dentária e flúor: uma relação do século XX. Cienc Saude Coletiva. 2000;5(2):381-92.

6 Fundação Nacional da Saúde (BR). Manual de fluoretação da água para consumo humano. Brasília: Fundação Nacional da Saúde; 2012.

7 Marimon MPC. O flúor nas águas subterrâneas da formação Santa Maria, na região de Santa Cruz do Sul e Venâncio Aires, RS, Brasil [tese]. Porto Alegre (RS): Universidade Federal do Rio Grande do Sul, Instituto de Geociências; 2006. 41 p.

8 Chioca LR. Ingestão crônica de flúor induz prejuízo nos testes de habituação e esquiva ativa em ratos [dissertação]. Curitiba (PR): Universidade Federal do Paraná, Programa de Pós-Graduação em Farmacologia; 2007. 48 p.

9 Frazão P, Narvai PC. Fluoretação da água em cidades brasileiras na primeira década do século XXI. Rev Saude Publica. 2017;51:47.

10 Santos MGC, Santos RC. Fluoretação das águas de abastecimento público no combate à cárie dentária. Rev Bras Cienc Saude. 2011 ; 15(1):75-80.

11 Cury JA. Uso do flúor e controle da cárie como doença. In: Baratieri LN, Monteiro Jr S. Odontologia restauradora: fundamentos e possibilidades. São Paulo: Santos; 2001. p. 33-68.

12 Silva, AF. Biodisponibilidade de fluoreto no plasma sanguíneo e saliva após ingestão de água ou de alimentos preparados com água fluoretada [tese]. Piracicaba (SP): Universidade Estadual de Campinas, Faculdade de Odontologia de Piracicaba; 2014.

13 Emmerich A, Freire AS. Flúor e saúde coletiva: 50 anos de fluoretação da água no Brasil. Vitória: Edufes; 2003.

14 Ministério da Saúde (BR). Secretaria de Atenção à Saúde. Departamento de Atenção Básica. Guia de recomendações para o uso de fluoretos no Brasil. Brasília: Ministério da Saúde; 2009. (Série A. Normas e manuais técnicos).
15 Rabb-Waytowich D. Water fluoridation in Canada: past and present. J Can Dent Assoc. 2009 Jul;75(6):451-4.

16 Frazão P, Narvai PC, organizadores. Cobertura e vigilância da fluoretação da água no Brasil: municípios com mais de 50 mil habitantes. São Paulo: Faculdade de Saúde Pública da USP; 2017.

17 Bellé BLL, Lacerda VR, De Carli AD, Zafalon EJ, Pereira PZ. Análise da fluoretação da água de abastecimento público da zona urbana do município de Campo Grande (MS). Cienc Saude Coletiva. 2009 jul-ago; 14(4):1261-6.

18 Prado JRS, Nunes JG, Hinnah SS, Marchetto M. Fluoretação em água de abastecimento e saúde pública. Eng Sci. 2014;2(1).

19 Souza BCO, Reis GS, Moimaz SAS. Legislação brasileira sobre o uso do flúor na saúde pública. In: $8^{\circ}$ Congresso de Extensão Universitária da UNESP; 2015.

20 Zilbovicius C, Ferreira RGLA, Narvai PC. Água e saúde: fluoretação e revogação da Lei Federal n. 6.050/ 1974. R Dir Sanit. 2017 nov-2018 fev; 18(3): 104-24.

21 Bleicher L, Frota FHS. Fluoretação da água: uma questão de política pública - o caso do Estado do Ceará. Cienc Saude Coletiva. 2006 jan-mar; $11(1): 71-8$.

22 Cesa K, Abegg C, Aerts D. A vigilância da fluoretação de águas nas capitais brasileiras. Epidemiol Serv Saude. 2011 out-dez;20(4):547-55.

23 Viegas AR, Viegas I, Fernandez RAC, Rosa AGF. Fluoretação da água de abastecimento público. Rev Ass Paul Cirurg Dent. 1987 jul-ago;41 (4):202-4.

24 Narvai PC, Frias AC, Fratucci MVB, Antunes JLF, Carnut L, Frazão P. Fluoretação da água em capitais brasileiras no início do século XXI: a efetividade em questão. Saude Debate. 2014 jul-set;38(102):562-71.

25 Ministério da Saúde (BR). Secretaria de Atenção à Saúde. Secretaria de Vigilância em Saúde. SB Brasil 2010: pesquisa nacional de saúde bucal: resultados principais. Brasília: Ministério da Saúde; 2012.

26 Kalamatianos PA, Narvai PC. Aspectos éticos do uso de produtos fluorados no Brasil: uma visão dos formuladores de políticas públicas de saúde. Cienc Saude Coletiva. 2006 jan-mar;1 11(1):63-9.

27 Anjos GAS, Fernandes GF. Fluoretação das águas de abastecimento público no Estado de Pernambuco: um resgate histórico. Odontol Clin Cient. 2015 jan-mar;14(1):559-64.

28 Ministério da Saúde (BR). Secretaria de Vigilância em Saúde. Monitoramento do parâmetro fluoreto na água para consumo humano e a situação da fluorose e cárie nas capitais brasileiras no ano de 2010. Bol Epidemiol. 2015;46(40): 1 - 10. 
29 Gusmão LHA. Cartografia dos distritos administrativos de Belém/PA com Google Earth [Internet]. Belém: Geocartografia Doigital Blogspot; 2018 [citado 2019 out 23]. Disponível em: http:// geocartografiadigital.blogspot.com/2013/05/ cartografia-dos-distritos.html.

30 Instituto Brasileiro de Geografia e Estatística. Cidades@: Belém: Pará [Internet]. Rio de Janeiro: IBGE; 2020 [citado 2020 dez 11]. Disponível em: https://cidades.ibge.gov.br/brasil/pa/belem/ panorama.

31 Soares JM, Valente MLMG, Silva VM, Mendes FC, Conduru MT, Pereira JAR. Soluções para o sistema de abastecimento de água para região metropolitana de Belém-PA [Internet]. 2015 [citado 2019 nov 15]. Disponível em: https:// www. researchgate.net/publication/268382044 SOLUCOES PARA O SISTEMA_DE ABASTECIMENT̄O_DE_ĀGŪA_PARA_REGIAO_METROPOLITANA DE BELEM - PA.

32 Videira FB, Silva AS. Análise da fluoretação das águas de abastecimento público na cidade de Belém do Pará [monografia]. Belém (PA): Universidade Federal do Pará, Instituto de Ciências da Saúde; 2003.

33 Secretaria de Saúde Pública (PA). Vigilância Sanitária. Laudo de análise de água 2005-2006. Belém (PA): SESPA; [data desconhecida].
34 Prefeitura Municipal de Belém. Plano municipal de saneamento básico de abastecimento de água e esgotamento sanitário de Belém-Pará: 2014. Belém: Secretaria Municipal de Saneamento; 2014.

35 Companhia de Saneamento do Pará. Ofício circular 468-P/2018. Belém: Companhia de Saneamento do Pará; 2018 nov 9. Assunto: Informação sobre paralisação do sistema de abastecimento público em Belém; 2018.

36 Barros WRC, Nascimento LS, Fontes RBC, Aguiar NL, Silva Jr IF, Souza CNP. Prevalência de cárie dentária na adolescência em Belém do Pará: uma perspectiva amazônica. Adolesc Saude. 2015 abr-jun; 12(2):59-68.

37 Martinez EHS, Frias AC, Mendes HJ, Olympio KPK. Per capita cost of fluoridating the public water supply in a large municipality. Rev Gauch Odontol. 2013 Out-Dec;61 (4):549-56.

38 Associação Brasileira de Engenharia Sanitária e Ambiental. Diretora nacional da ABES participa de reunião na Cosanpa sobre o uso de flúor em água de consumo humano [Internet]. Rio de Janeiro: ABES; 2018 [citado 2019 out 10]. Disponível em: http://abes-dn.org.br/?p=17429.

Recebido em / Received: 2/6/2020 Aceito em / Accepted: 12/3/2021 